\title{
Orofacial motricity in temporomandibular dysfunctions: an integrative approach to interdisciplinary intervention
}

Daniela Francisca Guzmán Baquedano(1) Carla Giovanna Rimassa Vásquez ${ }^{(1)}$

Giselle Andrea Castañón Sanz ${ }^{(1)}$

Carla Stefanía Flores Hernández ${ }^{(1)}$

1) Universidad de Valparaíso, San Felipe, Valparaíso, Chile.

Conflict of interests: Nonexistent

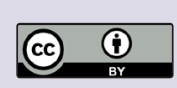

Received on: December 6, 2017 Accepted on: April 20, 2018

Mailing address:

Daniela Francisca Guzmán Baquedano

Los Naranjos 493. Villa La Doñita

Región de Valparaíso, San Felipe, Chile.

Código Postal:2171174

Email: daniela.guzman@uv.cl

\section{ABSTRACT}

Objective: to describe the speech-language therapist role in the interdisciplinary team in the intervention of Orofacial motricity in the temporomandibular dysfunction documented in scientific publications.

Methods: the search was conducted in well-known databases using the following terms or terminological associations: Temporomandibular dysfunction (TMD), stomatognathic system and TMD, Mastication, Speech and TMD. Interventions related to voice or temporomandibular joint indemnity were not included.

Results: the interventions indicated in the scientific publications are described, giving an account of the role of the speech pathologist in the TMD intervention team.

Conclusion: the therapist's intervention in Orofacial Motricity restores the stomatognathic system by addressing its functions. An isolated treatment approach from professionals overlooks the relationship of interdependence between function and structure. An appeal for an integrated and interdisciplinary work model, setting it free from the traditional fragmentary and multidisciplinary model, is made.

Keywords: Temporomandibular Joint Disorders; Stomatognathic System; Therapeutics 


\section{INTRODUCTION}

Human communication includes the full development of the speech function and the expression of language. The speech-language therapist practice has been primarily associated to one of these aspects: language. However, research findings in the Orofacial Motricity (OM), field, which has lately evidenced a considerable development, show that the MO is closely linked to the functions and structures of the stomatognathic system, so that any anomaly of it would generate communication alterations. However, $\mathrm{OM}$, more than a field by itself, should be considered as a framework encompassing several subdisciplines ${ }^{1}$. Temporomandibular Joint (TMJ) is the aspect common to all of them. Therefore the speech-language therapy field of work is at present much wider, as an OM specialist whose expertise allows an adequate intervention oriented to re-establish the stomatognathic functions: breathing, mastication, swallowing and speech become crucial. This is a recent field and it becomes necessary to assemble information about therapy of the temporomandibular dysfunctions carried out by multidisciplinary teams.

TMJ studies have been carried out for a long time in the dentistry and medicine fields. One TMJ affection called Temporomandibular Dysfunction (TMD), is a complex pathology encompassing a compound of articular and muscular dysfunctions of the craniofacial region. It shows diverse symptomatology, mainly characterized by articular and/or muscular pain, noises in the temporomandibular articulations and limited function. Besides it can appear with associated symptomatology such as craniofacial pain, vertigo, hypertrophy of the muscles involved in mastication, limited mouth opening, and block in the opening or closing of the TMJ, occlusal alterations ${ }^{2}$. In this sense, the traditional approach is multidisciplinary and has been focused on the structure.

Speech-language therapy publications have lately appeared and been added to those usually recognized from other disciplines, bringing a change of focus and new guidelines for TMD intervention. To this end, a bibliographic review of scientific publications was done in the present work, so as to describe the role of the speech-language therapist in the interdisciplinary team for the intervention of Orofacial Motricity in TMD, as documented in scientific publications.

\section{METHODS}

A bibliographic review concerning therapeutic intervention on TMD was carried out from January to June 2017. The purpose was to describe the role of the speech-language therapy in the interdisciplinary team for the intervention of Orofacial Motricity in TMD documented in scientific publications. Original papers were reviewed as well as bibliographic reviews. The search was carried out through the Lilacs, PubMed, SciELO, and Cochrane Library databases, selecting publications including the following terms, acronyms and terminological associations: temporomandibular dysfunction; TMD; stomatognathic system and TMD; mastication, speech and TMD. Finally, the criterion for inclusion in the sample was that the subject of the publication should correspond to speech-language intervention in TMD and publications that approach speech and mastication without mention of TMJ and TMD related to voice and speech were excluded.

\section{RESULTS}

The speech-language therapist has mainly been associated to the evaluation, diagnosis and rehabilitation of language disorders. However, on investigating the documentation concerning the studies about Orofacial Motricity (OM), the importance of the work of this professional in this field has begun to be recognized, as communication can be distorted because there is a close relationship between communicative indemnity and that of the stomatognathic functions and structures ${ }^{1}$. In this sense, the orofacial functions observed by an OM specialist speech-language therapist are: suction, swallowing, breathing, mastication and speech, which are closely related to the TMJ. The latter has been extensively studied by dentists, who during the last decade have begun to understand the need to include a speech-language therapist in the interdisciplinary teams for the intervention of Orofacial Motricity. Therefore, there are always more referrals of patients showing difficulties to swallow, or to speak (children, adolescents and adults). The point to be stressed here is that after the speech-language evaluation of patients who were referred (mainly due to alteration of swallowing or speech), it was found out that other functions were altered, such as pain in the temporomandibular joint or TMD, which were not the reason for the initial referral ${ }^{1}$. This is due to the fact that the TMJ forms part of a more complex system, 
the stomatognathic system, which shall be described below.

The jaw is the only movable bone of the craniofacial skeletal system inserted in the temporal bone, by means of its joint, and is able to carry out complex and synchronized movements. The components of this joint are: mandibular condyle, mandibular foramen, temporal joint tubercle, articular disk, ligament and nervous tilt connection $^{3}$. That said the TMJ is a predominant part of the stomatognathic system working together for the different orofacial functions. This joint carries out rotation movements when opening and closing the mouth, whether in horizontal, vertical or sagittal planes. The movements of translation are carried out when the jaw moves backwards and forwards, mainly in mastication and speech ${ }^{4}$.

One of the orofacial functions of interest for the speech-language therapist OM specialists is the speech articulation process, related to the range of mandibular action and therefore to the TMJ. In line with the ranges of action of the latter, the tongue can move freely and reach properly each articulation point associated to the production of phonemes. Now, when some interference is present at the mandibular level, which does not allow these spaces to be adequate, difficulties will appear both at the speech level as well as the $\mathrm{TMJ}^{5}$.

It must be taken into account that mandibular movements and positions are determined by three elements: temporomandibular joint, neuromuscular mechanism and the central nervous system. Therefore, it is important to know the muscles that intervene, so as to fully understand TMD physiopathology. The set of muscles that play a part are: temporal muscle, masseter and the lateral and medial pterygoid muscles ${ }^{6}$. Evidently, the free or adequate temporomandibular function requires a harmonious neuromuscular balance $^{6}$. When there is any dysfunction in some of these structures, functional and/or anatomic modifications shall very probably appear, this is more strongly evident in mastication and speech. However, the whole stomatognathic complex is affected and therefore alterations can generate changes in all the functions ${ }^{7}$. For example, mastication is relevant since it stimulates the growth, development and maintenance of the health of the stomatognathic system. In this sense, the strength, movement, time and type of mastication are influenced by diverse aspects, among them: food characteristics, morphology and functioning of the $\mathrm{TMJ}^{8}$.

On the other hand, the relationship between TMD and speech has been researched and relevant data have been established. Some studies have shown that in situations where a TMD is present, functional adaptations of speech can be generated, especially in the articulation of the phoneme $/ \mathrm{s} /{ }^{9}$. Therefore, it can be affirmed that the TMJ has a fundamental role in the speech process, because mandibular movements are possible arising from the biomechanics of this articulation ${ }^{10}$. In this way, the myofunctional intervention in TMD has been based on what has been done in the odontologic field, whose directives address generic and not specifically therapeutic aspects ${ }^{11}$. In this sense, it is possible to say that a first approach to speechlanguage therapy was to use diagnosis methods, but in time, the inclusion of therapeutic intervention methods has been observed.

The TMD clinical assessment carried out by the speech-language therapist is evidenced during the clinical examination, as the motor execution that happens during the communication or swallowing processes is observed. In this case, the professional assesses the involved morphology, linking the structural characteristics of mobility and spaces for action present during those functions ${ }^{9}$. This is backed by a study made on asymptomatic persons, on whom electromyography was carried out; the results arrived are that to carry out an opening for speech the average amplitude of $11 \mathrm{~mm}$, with protrusive components of $12 \mathrm{~mm}$ and retrusive ones of $5,7 \mathrm{~mm}$, and that deviations and laterality oscillate by $1 \mathrm{~mm}$ on the average. In other words, this study confirmed that the amplitudes carried out during communication (speech) require the integrity of the $\mathrm{TMJ}^{5}$.

The etiology of a TMD can be multifactorial, the causes found are: occlusion, traumatic lesions, degenerative lesions, skeletal muscle alterations, psychological factors and functional habits. All these factors can generate maladjustments at the TMJ level which imbalance the whole stomatognathic system. This is the basis of the importance of the speech-language therapy approach for these alterations ${ }^{6}$. Persons suffering some type of TMD often show limitations of the masticatory function; this causes functional asymmetry in the stomatognathic system, such as unilateral mastication, especially in the presence of occlusal alterations ${ }^{12}$.

A study proposed to research the functional characteristics of persons with temporomandibular dysfunctions of class II dentomaxillary deformities with indication of orthognatic surgery. After surgery and speech-language therapy treatment, it was found that 
$81 \%$ of the patient's evidenced functional improvement, which reveals the interdisciplinary work resulting from joint surgery and speech-language therapy ${ }^{13}$. Similarly, a study of subjects with ATM ankylosis showed that the myofunctional intervention directed to jaw and muscle mobility achieved restoration of the functions. The study highlighted that the achieved success was due to the work of an interdisciplinary team consisting of a speech therapist, surgeons, dentists and kynesiologists ${ }^{14}$.

Furthermore, a study carried out on patients with orofacial pain associated to disorders of the masticatory muscles, secondary to a TMD, highlights that the speech therapist work directed to intervention in the swallowing, breathing and speech functions was also able to simultaneously diminish the orofacial pain of the patients. Consequently, the study reveals the importance of the speech therapy intervention which approached the function as a first step; this allowed reaching muscular balance and reduce pain ${ }^{4,15}$.

In brief: it is important to highlight that the speech therapist's intervention has a significant role in the TMD and is part of the work of the interdisciplinary team. However, at present, the diagnosis is carried out by dentists and in the case of surgeries, other professionals take part, such as the maxillofacial surgeon. Now, speech therapy expertise in this field allows to point out that this professional can not only warn, investigate or propose the presence of a TMD, but also intervene employing OM therapy, whose objectives are: manage the pain, mobilize soft tissues, increase the functionality of the different ranges of mandibular mobility, improve mandibular stability and provide a distinct approach of the movements of the head, jaw and tongue, with active and passive exercises ${ }^{4}$.Therefore, during the past years, the practice of the speech-language therapy has widened its scope of intervention, which now includes Orofacial Motricity, from the proposed TMD diagnosis to its intervention employing an integration viewpoint.

\section{DISCUSSION}

According to the review of the literature, the initial speech therapy in TMD had a scarcely systematized viewpoint. In time, and thanks to practices based on evidence, the field of Orofacial Motricity in TMD has broaden its vision and generated scientifically supported answers as to its approach, so greater systematization has been achieved ${ }^{16-18}$. This has resulted in that in some countries of Latin America there is a greater number of specialists who recognize the importance of the participation of the speech-language therapist in these disorders, enabling an adequate or early detection of the pathology. When this awareness does not exist, patients do not arrive immediately for consultation and it is only possible to detect them by derivations of other functions (usually speech and swallowing alterations). Therefore, an early investigation would avoid that the TMD syndrome reached more severe and in some occasions irreversible levels ${ }^{19}$.

It is highly relevant to mention that there are other orofacial functions that generate pain complaints. In this sense, it is necessary to strengthen the knowledge about speech-language therapy in this area, to recognize the symptomatology of a TMD, not focusing on referral reasons only (swallowing/speech), since clinical experience in $\mathrm{OM}$ highlights that a mastication disorder, for example, can trigger or be associated to this symptom. However, at present, patients complaining about pain, do not come to the speech therapy consultation until they are assessed for another reason. During the clinical assessment sensitivity to pain is revealed in the craniofrontal region and the chain of masticatory muscles by means of palpation. Then, an appropriate examination allows distinguishing a specific alteration of communication from another disorder secondary to TMD, as this determines the appropriate treatment to be carried out. Therefore, it is of crucial importance on the part of other professionals and the speech-language therapists not specialist in $\mathrm{OM}$ to know the role of speech-language therapy described above, for an efficacious and opportune referral ${ }^{15,20}$.

Finally, concerning the way to impede future structural alterations, it is necessary to emphasize that prevention and early diagnosis are fundamental in these clinical patterns. The findings in diverse studies indicate that in the assessment of the stomatognathic, system by the speech-language therapist as that of other intervening specialties, the participants must take care to approach both the functional and anatomic aspects; this involves a change towards an integral vision in agreement with that assumed by an Orofacial Motricity speech-language specialist therapist ${ }^{21}$.

Generally speaking, human beings have a great capacity to adapt to new situations brought about in different contexts. At a more specific level, this also happens in the stomatognathic system, as for example, the adaptations occurring as a consequence of a TMD, evidenced during mastication and speech. Then, when the above occurs, compensatory transformations and adaptations of the functions take place. In fact, 
it is known that in such cases, the incision, grinding, number of cycles, speed and mastication pattern are modified.

Concerning speech, articulation distortions of phonemes linked to a TMD can be found. In this bibliographic review, we found scant information concerning the role of the speech-language therapist and of the interdisciplinary approach in this field, which reveals that TMD intervention is a relatively new field and is being developed. Therefore, the challenges for speechlanguage therapy are: theoretical-practical training; promotion of new scientific research and diffusion of the practice of the Orofacial Motricity specialist.

Concerning research, it would be helpful to have more information from all the fields, in order to better understand the TMD and promote knowledge of it in the various professions involved, so as to work using an interdisciplinary approach and provide a better quality of life to the patients. In this sense, the proposal that arises is that dentists, kinesiologists and speechlanguage therapists should carry out interdisciplinary work to optimize professional resources for anamnesis, evaluation, diagnosis and treatment.

\section{CONCLUSION}

Considering the professional training of speechlanguage therapists, it is possible to affirm that they are the appropriate specialists for the diagnosis, investigations and rehabilitation of the TMD. Thus, a step to be followed would be the increase of OM speechlanguage therapist specialists. This, because the clinical assessment of these specialists within the interdisciplinary team allows detecting the repercussions that may exist in stomatognathic functions, and their relationship with communicative functions, so as to carry out the adequate treatment for each case. In other words, the issue that is raised by the myofunctional intervention is to propitiate the re-establishment of the structure approaching its functions, as a total recovery cannot be reached while these remain distorted. Therefore, the isolated intervention of the professionals overlooks the visualization of the pathology as a whole, as there is an interdependency relationship between function and structure. For this reason, an integration viewpoint is proposed, understanding that an interdisciplinary rather than a multidisciplinary approach is required.

\section{REFERENCES}

1. Marchesan I. Distúrbios da motricidade oral. En: Russo I (ed). Intervenção fonoaudiológica na terceira idade. Rio de Janeiro: Revinter; 1998. p. 83-100.

2. Salcedo F. Rehabilitación oral en paciente con disfunción temporomandibular relacionada a factores oclusales. In Cres. 2014;5(1):103-11.

3. Bianchini E. Articulação temporomandibular e fonoaudiologia. En: Bianchini E (ed). Articulação temporomandibular: Implicações, limitações e possibilidades fonoaudiológicas. Segunda Edição. Brasil: Pró-Fono; 2010. p. 9-17.

4. Martha I, Torres A. Manejo fonoaudiológico de los trastornos de ATM. Rev Est. 2005;13(1):36-41.

5. Bianchini E, Paiva G, Furquim C. Movimentos mandibulares na fala: interferência das disfunções temporomandibulares segundo índices de dor. Pro-Fono R Atual. Cientif. 2007;19(1):7-18.

6. Quinto C. Classificação e tratamento das disfunções temporomandibulares: qual o papel do fonoaudiólogo no tratamento dessas disfunções. Rev. CEFAC. 2000;2(2):15-22.

7. Bianchini E. Fonoaudiologia, odontologia e disfunções da ATM. En: Bianchini E (ed). Articulação temporomandibular. Implicações, limitações e possibilidades fonoaudiológicas. Segunda edição. Brasil: Pró-Fono; 2010. p. 18-49.

8. Felício C, Couto G, Ferreira C, Mestriner J. Confiabilidade da eficiencia mastigatória com beads e correlação com a atividade muscular. Pro-Fono R Atual. Cientif. 2008;20(4):225-30.

9. Aparecida R, Bianchini E. Verificação da interferência das disfunções temporomandibulares na articulação da fala: queixas e caracterização dos movimentos mandibulares. Rev Soc Bras Fonoaudiol. 2007;12(4):274-80.

10. Marchesan I. Atuação fonoaudiológica nas funções orofaciais: desenvolvimento, avaliação e tratamento. En: Andrade C, Marcondes E (eds). Fonoaudiologia em Pediatria. São Paulo. Sarvier. 2003. p. 3-22.

11. Bianchini E. Fundamentos de anatomía e biomecanica. En: Dias JB (ed). Articulação temporomandibular. Implicações, limitações e possibilidades fonoaudiológicas. Segunda Edição. Brasil: Pró-Fono; 2010. p. 53-80.

12. Felicio C, Melchior M, Silva M, Celeghini R. Desempenho mastigatório em adultos relacionado com a desorden temporomandibular 
e com a oclusão. Pro-Fono R Atual. Científ. 2007;19(2):151-8.

13. Pereira J, Bianchini E. Functional characterization and temporomandibular disorders before and after orthognatic surgery and myofunctional treatment of Class II Dentofacial deformity. Rev. CEFAC. 2011;13(6):1086-94.

14. Marzotto S, Bianchini E. Anquilose temporomandibular bilateral: aspectos fonoaudiológicos e procedimentos clínicos. Rev. CEFAC. 2007;9(3):358-66.

15. Fernandes C, Cunha M. A escuta terapêutica fonoaudiológica: estudo de caso clínico de paciente com dor facial crônica. Distúrb Comun. 2009;21(1):93-9.

16. Bianchini E. Ajuda fonoaudiológica. En: Dias J (ed). Articulação temporomandibular. Implicações, limitações e possibilidades fonoaudiológicas. Segunda edición. Brasil: Pró-Fono; 2010. p. 323-63.

17. Pavez A, Silva T. Fonoaudiología y estética facial: experiencia de Brasil en la Atención Primaria de Salud. Revista Chilena de Fonoaudiología. 2015;14:45-54.

18. Armijo-Olivo S, Pitance L, Singh V, Neto F, Thie $\mathrm{N}$, Michelotti A. Effectiveness of manual therapy and therapeutic exercise for temporomandibular disorders: systematic review and meta-analysis. Physical Therapy. 2016;96(1):9-25.

19. Melchor M, Machado B, Zanandréa B, Magri L, Mazzetto M. Effect of speech-language therapy after low-level laser therapy in patients with TMD: a descriptive study. CoDAS. 2016;28(6):818-22.

20. Rodrigues CA, Melchior OM, Magri LV, MestrinerJr $\mathrm{W}$, Mazzetto MO. Is the masticatory function changed in patients with temporomandibular disorder? Braz. Dent. J. 2015;26(2):181-5.

21. Marzotto S, Bianchini EM. Anquilose temporomandibular bilateral: aspectos fonoaudiológicos e procedimentos clínicos. Rev. CEFAC. 2007;9(3):3583-66. 